Revista Geográfica Digital. IGUNNE. Facultad de Humanidades. UNNE. Año 13. N0 25. Enero - Junio 2016. ISSN 1668-5180 Resistencia, Chaco

\title{
La Geografía de la Población en el Marco de las Corrientes del Pensamiento Geográfico
}

Dra. Celmira Esther Rey

Cátedra Geografía de la Población.

Profesorado y Licenciatura en Geografía.

Departamento de Geografía. Facultad de

Humanidades. Universidad Nacional del

Nordeste. UNNE

Publicado en formato digital: Dra. Celmira Esther REY. LA GEOGRAFÍA DE LA POBLACIÓN EN EL MARCO DE LAS CORRIENTES DEL PENSAMIENTO GEOGRÁFICO. PRODUCCIÓN EN DOCENCIA. Revista Geográfica Digital. IGUNNE. Facultad de Humanidades. UNNE. Año 13. № 25. Enero - Junio 2016. ISSN 1668-5180 Resistencia, Chaco.

En: http://hum.unne.edu.ar/revistas/geoweb/default.htm 


\section{La Geografía de la Población en el marco de las corrientes del pensamiento geográfico}

\section{INDICE}

Palabras preliminares

Agradecimientos

Presentación

- Las principales corrientes del pensamiento geográfico y sus referentes -Institucionalización de la Geografía. Introducción como disciplina en el sistema educativo

- Configuración de escuela nacionales en Geografía

- Renovación de la Geografía $\longrightarrow$ Crisis?

- ¿Las Geografías?

¿ Y el papel de la Geografía de la Población dentro de las corrientes del pensamiento geográfico? 


\section{Presentación}

Con esta presentación se pretende inducir a la reflexión acerca del desenvolvimiento de la Geografía de la Población en el marco de la de las oscilaciones entre diversas posiciones que han marcado a la Ciencia Geográfica, desde sus primeros indicios hasta su consolidación como ciencia. Por tanto, invita a discernir y esclarecer el estado del conocimiento de esta especialización del saber geográfico, a partir de una revisión epistemológica de sus fundamentos, del análisis sus conceptos, teorías y trascendencia metodológicas con sus respectivas técnicas más representativas.

Se ofrece realizar un ejercicio crítico y prescriptivo acerca de la evolución del pensamiento geográfico en el ámbito de la Geografía de la Población, a los efectos de generar una reconstrucción de los procesos implícitos en los saberes propios de la Geografía y de la manera de pensar de los científicos según época y contexto socio territorial. El objetivo es identificar los principales pensamientos de científicos que construyeron el saber sistematizado conocido y al se ha podido acceder hasta la fecha . 


\section{PRESENTACIÓN}

\section{Por Mgtr. Emilas Lebus}

Profesora y Licenciada en Geografía. Magister en Epistemología y Metodología de la Investigación Científica. Doctoranda en Ciencias Cognitivas. Docente de Grado e Investigadora en la UNNE. Docente de Postgrados en varias universidades argentinas.

En primer lugar, agradezco a la Dra. Celmira Rey por haberme solicitado que actúe como revisora de la producción de este material didáctico, de su autoría, elaborado para su cátedra "Geografía de la Población" que forma parte del plan de estudios del Profesorado y de la Licenciatura en Geografía de Facultad de Humanidades, Universidad Nacional del Nordeste (UNNE). Esta invitación, además de ser un honor para mí, es un desafío en el sentido de que implica proyectar una mirada epistemológico-metodológica hacia los estudios de población desde la perspectiva geográfica.

Estas líneas constituyen una apreciación general de su trabajo, al que concibo como un rico aporte para alumnos y profesores no sólo de la UNNE, sino de distintas universidades y centros de estudios que tratan sobre los aspectos de población en Geografía.

El tema abordado en este material didáctico versa sobre la evolución de los estudios geográficos vinculados a la población (distribución, cambios demográficos, movilidad, nuevas tendencias, etc.). Cabe destacar que esta indagación por la población como una cuestión intrínseca al espacio geográfico mismo -hoy asumido como objeto de estudio de la Geografía- no estaba presente en los abordajes geográficos de la manera en que hoy se reconoce su importancia: claro está, sin la intervención humana en el espacio no hay espacio geográfico. Éste integra tanto aspectos y fenómenos naturales como objetos y acciones antrópicas. El espacio es "producto" (o resultante) de ese entramado complejo de interrelaciones.

Sin embargo, con esta génesis de los estudios de la población dentro del campo geográfico, va emergiendo, poco a poco, un cúmulo de convicciones fuertes que reivindican la necesidad de "ligar" la población a su base geográfica, es decir, un esfuerzo por hallar su especificidad-dentro de la misma Geografía- sin confundirse con Demografía ni con Sociología, ni con ninguna otra ciencia social. 
En este sentido, el material elaborado por la Dra. Celmira Rey muestra cómo fue forjándose la aparición de los "asuntos humanos" en la Geografía a la par que iba desarrollándose el pensamiento geográfico. Se ocupa así de cuáles fueron sus precursores, quiénes, dónde y cuándo se consolidaron los estudios de población en relación a su intrínseca "espacialidad", constituyéndose, poco a poco, como una parte relevante (subrama) de la investigación geográfica dentro de su rama principal conocida como Geografía Humana o "Antropogeografía", es decir, geografía del hombre. Las filminas que se suceden en esta presentación muestran los avatares por los que ha transitado esta "emergencia" que, si bien aparece tratada, de modo pionero, en la obra de Carl Ritter, toma forma y cuerpo, esto es, teorías y métodos, recién al finalizar el siglo XIX y, sobre todo, en la primera parte del siglo XX. En contenido de este material, muestra, en toda su extensión, cómo fue pensándose la cuestión poblacional en el campo geográfico.

Entre los laberínticos recorridos de una ciencia que va abriéndose camino, como la Geografía, experimentando un despedazamiento de su campo de estudio en un tiempo -como el de fines del siglo XIX- en que cada disciplina trataba de definirse a sí misma, la Geografía de la Población entra en escena como una parte importantísima e ineludible de la investigación y la enseñanza geográficas. El lector notará, en tal sentido, que esta "tensión" (a modo de contradicción interna) en la propia Geografía, va manteniéndose a partir de esa evolución que comienza en la primera parte del siglo XIX. ¡Y podría haber comenzado mucho antes!, con el programa de trabajo que se había trazado -tempranamente, casi dos siglos antes- Bernardo Varenio, si no hubiese ocurrido su prematura muerte (con apenas 28 años de edad), lo que hubiera sentado las bases de lo que luego sería la Geografía Humana. Ese proyecto es retomado por Ritter, por Ratzel y por Vidal de la Blache.

De ahí en más, la historicidad de los estudios que hoy llamamos "Geografía de la Población", como un capítulo de indagación destacado dentro de la Geografía Humana, refleja los vaivenes de métodos, discusiones teóricas, delimitación de sus contenidos específicos, entre otros aspectos, que son fácilmente identificables en su evolución más reciente: desde mediados del siglo XX en adelante. 
En este proceso de re-situar la Geografía de la Población, como aquellos estudios que pretenden explicar los hechos de distribución, estructura, cambio y movilidad de la población por su inevitable referencia a un sustrato físico, territorial o de base geográfica, se nota no sólo la actitud de búsqueda constante de perfeccionamiento de los métodos y categorías específicas de análisis, sino una "apertura" a nuevos temas-problemas de interés para el geógrafo, tales como el fenómeno de las migraciones, el envejecimiento de la población (que experimentan algunas sociedades) con los consiguientes efectos y demandas que ello genera, así como los problemas del hábitat, las cuestiones de género, los desplazados forzosos, los refugiados, entre otros procesos actuales (y actuantes) en un mundo global.

Es desde estos nuevos contenidos - de investigación y de enseñanza- donde la Geografía de la Población emerge "revitalizada", permitiendo no sólo enriquecer la mirada compresiva-explicativa del espacio geográfico -objeto de nuestra ciencia- sino también anticipando cómo la Geografía puede hacer aportes significativos a otras ciencias (sociales y naturales).

El decurso de los acontecimientos que forjaron la evolución de esta parte relevante del conocimiento del espacio dentro de la Geografía y en su desarrollo fronterizo de co-evolución con otras disciplinas -hoy ciencias independientes de la nuestra- es el eje del tratamiento que la Dra. Rey hace en este material. Su importancia radica en que sitúa al alumno (y al estudioso de cuestiones de población) en el lento y dificultoso proceso formativo como subrama clave de la Geografía, que nunca perdió la conexión con sus orígenes: su pertenencia al campo geográfico por la simple razón de que la población es un componente insoslayable de la organización y dinamización de las "relaciones geográficas" en la superficie terrestre.

Es decir, la Geografía de la Población conservó y preserva, a todas luces, la savia que le da vida: su conexión con las "raíces" profundas que ligan al hombre con la Tierra (cuestión que preocupaba a los "pioneros" (Padres) de la ciencia geográfica; pero, al mismo tiempo, ha ido creciendo y haciendo circular esta savia vivificante para revitalizarse a sí misma, abriéndose como la copa de un árbol hacia la atmósfera para respirar el aire que le permita una existencia renovada. Esa atmósfera está dada, hoy día, por los planteos, de distinta índole, que provienen de la interconexión de los procesos que trae aparejado un mundo global y, con ello, de las nuevas formas de pensar. 
Es desde allí donde se establece el diálogo de la Geografía de la Población con nuevos temas, métodos, conceptos... y en ese movimiento que le da vida, hace circular estos nuevos nutrientes y los cimenta -resituándolos- en sus raíces geográficas mismas, es decir, como "hechos" de la superficie terrestre (o -diría Tricart- de la "epidermis" de la Tierra, hoy vuelta tan frágil, sutilmente interconectada y, por ello, tan compleja) que exige la mirada penetrante de quien está preparado para captarla en su "diversidad" y "complejidad intrínseca", abriéndose, al mismo tiempo, al diálogo inter-ciencias, es decir, propendiendo a estudiar esos hechos poblacionales desde la Geografía pero con una mirada interdisciplinaria.

Interpreto que estas transformaciones epistémicas, metodológicas, sociales y pedagógicas son las que pretende transmitir la Dra. Rey en este material. Invito pues a los lectores a una lectura paciente para captar los cambios en el pensamiento geográfico sin perder la esencia.

Agradezco por haberme confiado la observación crítica y constructiva hacia su producción; tarea que me ha servido también como un medio de enriquecimiento personal y profesional.

Mgtr. Emilas Lebus

Otoño de 2016 


\section{Agradecimientos}

Este trabajo, fruto de muchas horas de lectura, análisis, comprensión y puesta en consideración a los estudiantes, durante el dictado de la Cátedra, se realizó gracias a la colaboración de mis colegas del Departamento e Instituto de Geografía de la Facultad de Humanidades, UNNE, y en particular por el aliento brindado por la Magister Emilas Lebus. No me caben dudas de lo importante de haber decidido pedirle que revisara mi trabajo. Le ha dado un realce y distinción más allá de las expectativas planteadas al momento de escribirlo. Agradezco infinitamente su delicadeza, dedicación y paciencia para con las observaciones realizadas, pero por sobre todo, el cariño demostrado en ocasiones del trabajo institucional donde, al encontramos, empezamos a pensar juntas este desafío de ser geógrafas en un contexto complicado que muchas veces, por diversas demandas, nos impide profundizar y producir en equipo.

Gracias Emilas Lebus! por "mirar" y "mirarme", ya que al decir del filósofo Vázquez Rocca, Adolfo, 20005, "Somos, en este sentido, ser para otros y no sólo por la teatralidad propia de la vida social, sino porque la mirada del otro nos constituye, en ella y por ella nos reconocemos. La constitución de nuestra identidad tiene lugar desde la alteridad, desde la mirada del otro que me objetiva, que me convierte en espectáculo. Ante él estoy en escena, experimentando las tortuosas exigencias de la teatralidad de la vida social. 
La Geografía de la Población en el marco de las corrientes del pensamiento geográfico

Para comenzar a reflexionar ...

* Paradigma se refiere a la fuente de los métodos, problemas y normas de resolución aceptadas por cualquier comunidad científica madura, en cualquier momento dado.

Es oportuno destacar que un paradigma fija una manera de enfocar la realidad objeto de estudio, que los distintos paradigmas son perspectivas del pensamiento, de la práctica de la investigación, son miradas, formas de interpretar la realidad geográfica. (Lebus,2016). Hace referencia, por ejemplo, cuando se habla que tal geógrafo se adhiere a la corriente de pensamiento del posibilismo o determinismo.

Un nuevo paradigma frecuentemente hace necesaria una redefinición de la ciencia correspondiente.

\section{Ejemplos:}

1- problemas antiguos pueden relegarse a otras ciencias o ser declarados "no científicos"

2- problemas triviales o inexistentes, pueden convertirse en un nuevo paradigma. 
1. Principales corrientes del pensamiento geográfico y sus referentes

Los fundadores de la Geografía moderna, son Humboldt y Ritter. Referentes indiscutidos por su fundamental aporte para el desarrollo de la Geografía comparada.

\begin{tabular}{c|c}
\hline POSITISMO & HISTORICISMO \\
\hline $\begin{array}{c}\text { HUMBOLDT (naturalista) } \\
\text { Precursor de la Geografía General, antes } \\
\text { que él, Bernhardus } \\
\begin{array}{c}\text { Varenius:1622/50.Geógrafo alemán, da } \\
\text { nacimiento a la Geografía científica, vale } \\
\text { decir, formula principios y métodos, } \\
\text { estudiando la conexión causal de los hechos } \\
\text { geográficos }\end{array}\end{array}$ & $\begin{array}{c}\text { Fundó la Sociedad Berlinesa de Geografía. } \\
\text { Logró conceder el rango científico a la } \\
\text { Geografía hasta ese momento }\end{array}$ \\
$\begin{array}{c}\text { Gesvalorizada, al considerar que esta } \\
\text { disciplina es, según el autor, la ciencia de las } \\
\text { relaciones espaciales, que busca establecer } \\
\text { causas y determinaciones, y no se limita a } \\
\text { los fenómenos físicos sino que incluye } \\
\text { también los relativos a la actividad del } \\
\text { hombre (Moraes, 1989). }\end{array}$
\end{tabular}


RATZEL ( alemán).

Fundador de la Geografía Humana En 1882, escribe Antropogeografía".

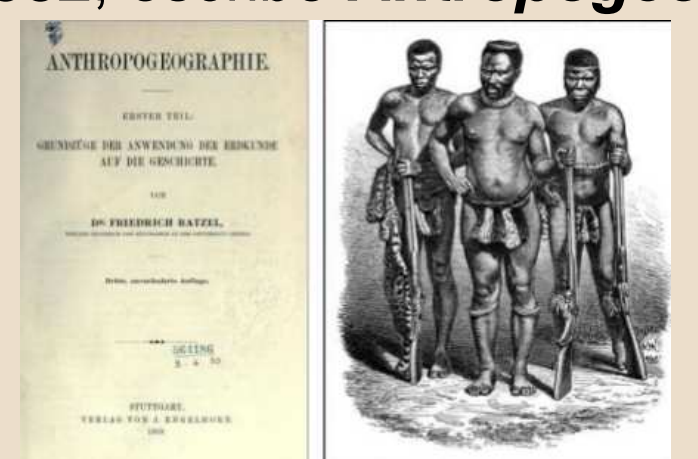

«El suelo regula la vida de los pueblos, con cierta brutalidad. Un pueblo debe vivir sobre el suelo que le ha tocado, debe morir en él y experimentar su ley". Inserta el concepto de distribución de hechos geográficos, entre ellos de la población.

Sostiene que recursos de un país condiciona el desarrollo, el progreso de este. Si bien lo hace con un criterio determinista, gracias a su vigorosa defensa $y$ encendidos debates, contamos hoy con la Geografía Humana y con el carácter humanístico de la Geografía.(Cuadra,2011).

\section{VIDAL DE LA BLACHE (francés)}

Formador de la Escuela Geográfica Francesa y fundador de la Revista Annales de géographie (1891).

Escribe: Cuadro de la Geografía de Francia» 1903 como introducción a la historia de Francia de Ernest Lavisse. «Principios de Geografía Humana» (1922) y «La Francia del Este» (1917).

Catedrático de geografía en la universidad de La Sorbona, desde 1898 hasta 1908. Desde la cátedra de La Sorbona alcanzaría gran prestigio, lo que le permitió impulsar la geografía en Francia, con la creación de la Escuela Geográfica Francesa con discípulos como Jules Sion, Jean Brunhes, Albert Demangeon o Emmanuel de Martonne. 


\section{Legado de Humboldt y Ritter}

* Formación de la Geografía como rama independiente del conocimiento.

* Sus obras componen la base de la Geografía tradicional.

* Sistema para organizar el conocimiento: acopiar material objeto de observación y dar coherencia sometiéndolo a leyes de causa - efecto.

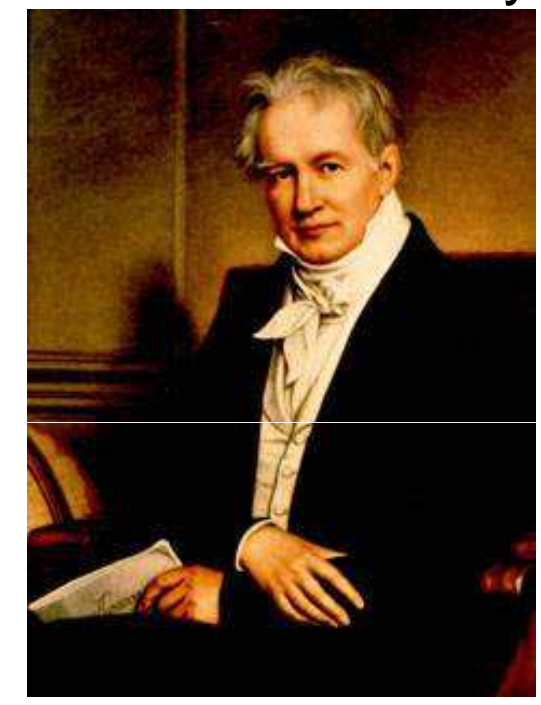

Alejandro de Humboldt (Alemán)
*Preocupados por la búsqueda de las "relaciones" que se establecían en la realidad geográfica, además de que ambos desarrollaron los principios de la Geografía, tales como la localización y la comparación,entre otros. (Lebus, 2016)
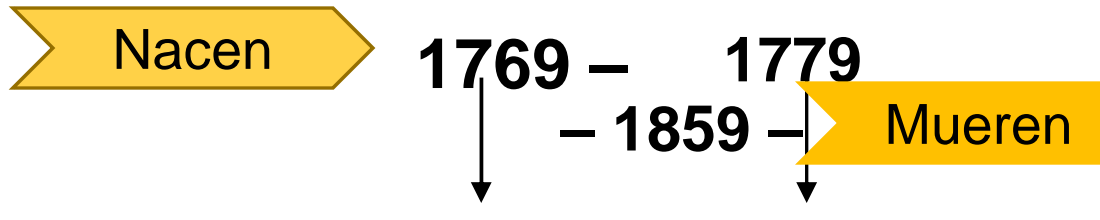

90 años 80

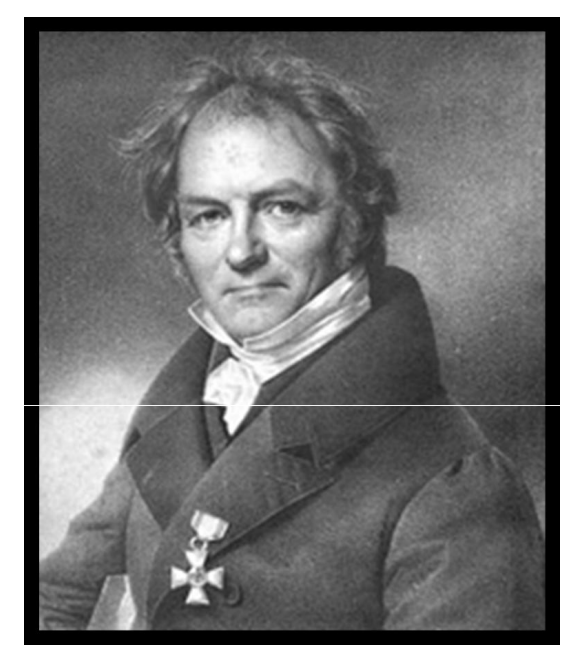

Carl Ritter

(Alemán) $1779-1859-$

Tras la muerte de Humboldt y de Ritter, se genera un período (de unas dos décadas aproximadamente) en que otras ciencias pretenden arrebatar la parte humana de la Geografía. Es decir, que todavía la Ciencia Geográfica, por lo menos en lo que respecta a su objeto de estudio, no estaba plenamente "consolidada". (Lebus, 2016) 


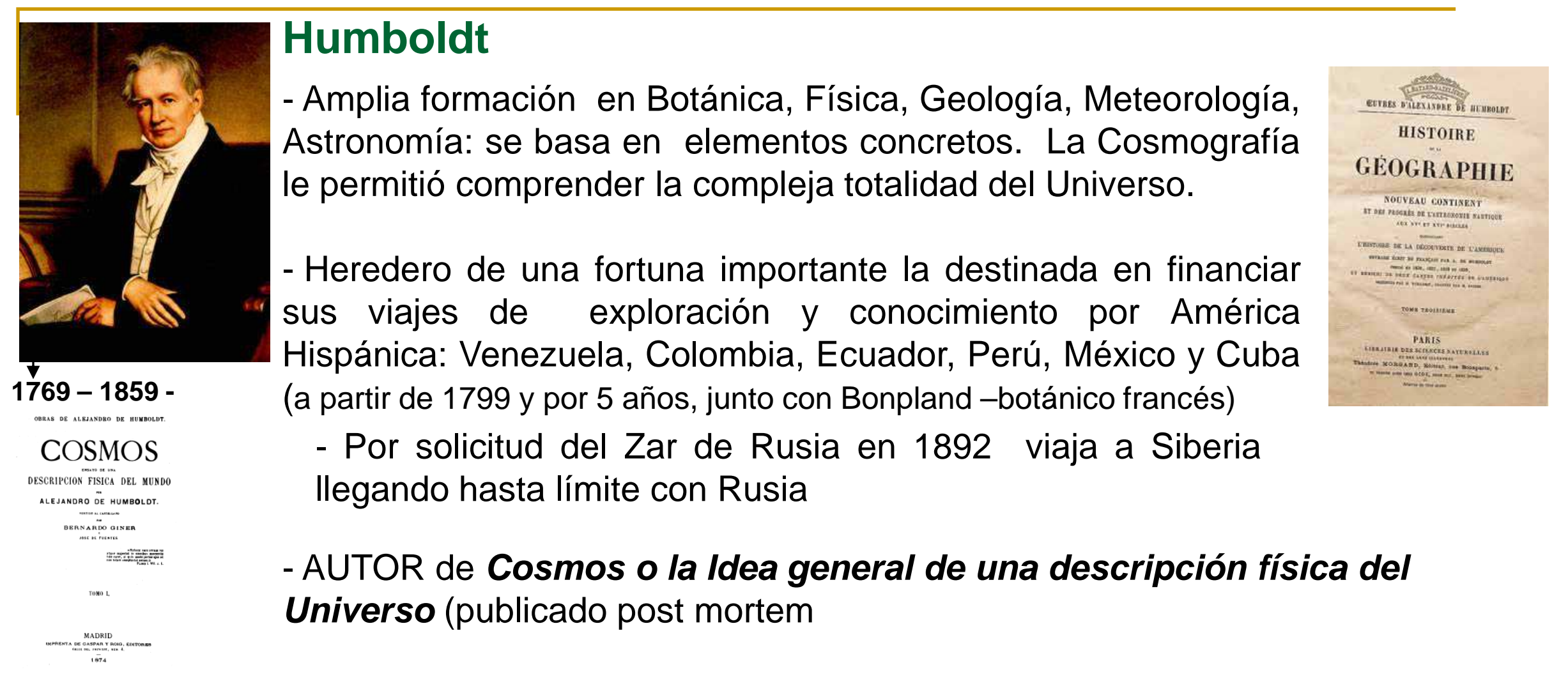

* Geografía ciencia integradora que permite demostrar de un modo experimental (observación) la armonía de la naturaleza. Busca, dentro del caos aparente, fenómenos inconexos, una armonía que procedente de relaciones complejas entre elementos diversos que componen la Tierra.

* Visión global de la Tierra: como un todo orgánico, en que todas sus partes son interdependientes. Esta visión tiene que ver con el contexto de donde provenía la formación de Humboldt: el ROMANTICISMO. (Lebus, 2016) 


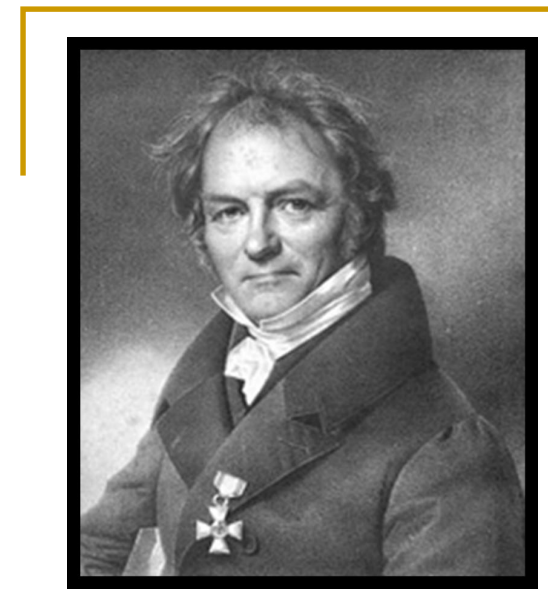

1779 - $1859-$

\section{Ritter}

- Formación filosófica e histórica

- En 1817 publica el primer volumen de su gran obra Die Erdkunde

"o Geografía general comparada"

- Primer profesor universitario En 1820 es designado profesor de la 1ํ cátedra de Geografía en la Universidad de Berlín, fue, en tal sentido, un pionero de la "institucionalización" de la Geografía)

*Visión antropocéntrica la Tierra es el teatro en el que se desarrolla la actividad del Hombre en su caminar hacia Dios ( carácter teleológico).

La naturaleza no es el único poder causal y que el hombre mismo es en la superficie de la tierra es un agente de transformación $y$ de vida.

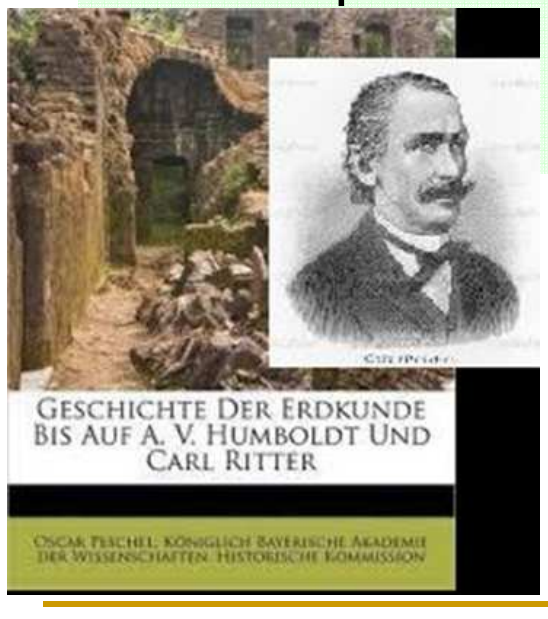

"NATURALEZA - HOMBRE:

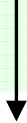

2 términos inseparables

* Define la región: unidad física, luego incluye al Hombre intentando demostrar como él, con sus destrezas materiales y mentales a su alcance, se adapta y usa su hábitat. 
* Aportes metodológicos:

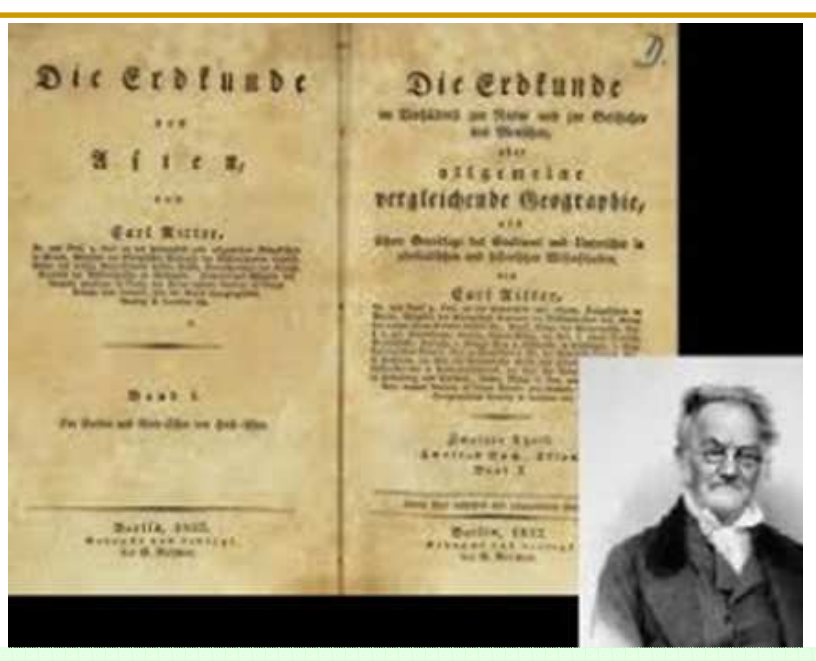

1. Valoración de los datos de observación sobre las conjeturas o hipótesis.

1. Modelar los datos observados por medio de un principio de organización consistente en subrayar la relación Hombre con el medio y descubrir la unidad subyacente dentro de la multiformidad.

2. No apresurarse en teorizaciones sin antes pedir a la Tierra sus leyes. Aquí se aprecia las ideas ambientalistas, vale decir la consideración de los fenómenos físicos como determinantes de los hechos humanos. 


\section{La institucionalización de la Geografía}

Tras la muerte de Humboldt y Ritter en 1859 se asiste a la crisis del desarrollo del conocimiento geográfico

Siglo XIX (segunda mitad): no goza de estatus científico reconocido

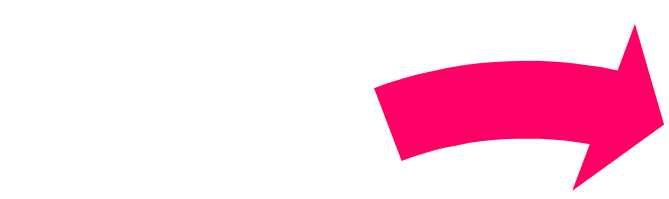

Nacionalismo

* Exige generalización de la

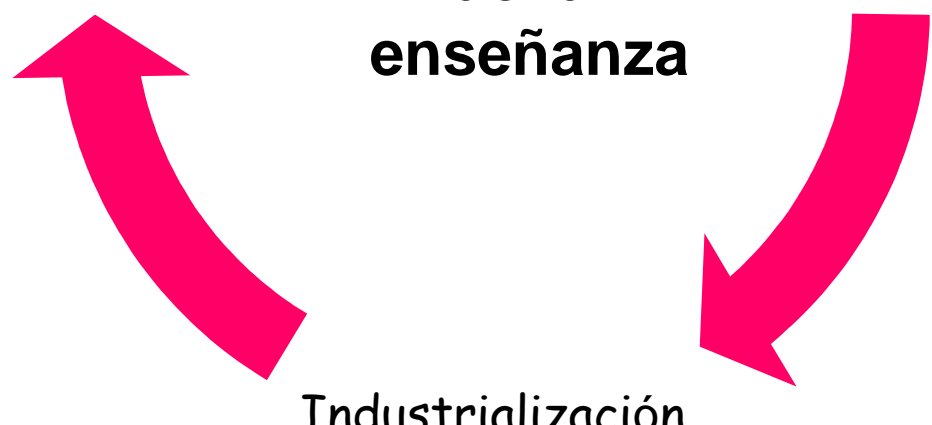

* 1 Congreso Internacional Amberes - 1871

Expansionismo

Representación comunidades de geógrafos 1922

\section{Revistas}

Indicador de desarrollo científico

* Sociedades geográficas

Cuentan con medios - producción científica. Impulsan presencia en la universidad 


\section{Configuración de escuelas nacionales en geografía}

* Debilidad teórica y conceptual (aceptación reducida de los planteamientos)

Preocupa la creciente la tendencia a un "especialismo" académico, en las que las partes emigran progresivamente hacia otras ciencias (físico 0 sociales) y se vuelve cada vez más difícil identificar un tronco disciplinar común. Porque las consecuencias de este distanciamiento interno no son puramente académicas: desprovista de un objeto compartido y sólidamente definido, la imagen de la geografía se difumina, se vuelve confusa o irreconocible no sólo para las demás disciplinas o especialistas académicos sino, par el público no académico, con lo que reconocimiento social se debilita . (Stoddart, David, 1994).

* Refleja idiosincrasia e intereses relacionados con el poder de cada país y de cada escuela geográfica

* Después de 1945:Concepto de escuelas nacionales de geografía entra en crisis frente a:

-Globalización económica

-Ciencias Sociales: adquieren propia metodología

Incorporación de Geografía en universidad 


\section{Escuela alemana:Determinismo Geográfico:}

- Discípulo de Ritter

- Busca leyes generales que expliquen todos los fenómenos geográficos.

- Libertad humana condicionada y dirigida por factores del medio

- influencia de condiciones naturales sobre la evolución de las sociedades

Friedrich Ratzel

(1844-1904)

\section{Artífice de Geografía Humana}

-Toma de Herder el ideal nacionalista y la idea de la Tierra como "teatro de la humanidad". - -

- Formula concepto de territorio, entendido como la porción de superficie terrestre apropiada por un grupo humano

-Intelectual comprometido con proyecto estatal: geopolítica

-Introduce idea Espacio vital expresa la necesidad de territorio de una determinada sociedad, -variable según sean su bagaje tecnológico, sus efectivos demográficos o los recursos naturales -disponibles (Moraes, 1989

-Formación en ciencias naturales:

-visión naturalista reduce al Hombre en el mismo estatus que cualquier otro ser vivo.

-busca la causalidad de fenómenos humanos del mismo modo que las ciencias de la naturaleza

- Influenciado por ideas :

- evolucionistas de Haeckel (Alumno de Darwin y profesor de zoología de Ratzel) -Geógrafos norteamericanos y rusos (1ํㅡㄹ decenios S. XIX)

Define el ecúmene

Origina doctrina ambientalista: naturaleza no es factor determinante sino soporte de la vida humana 


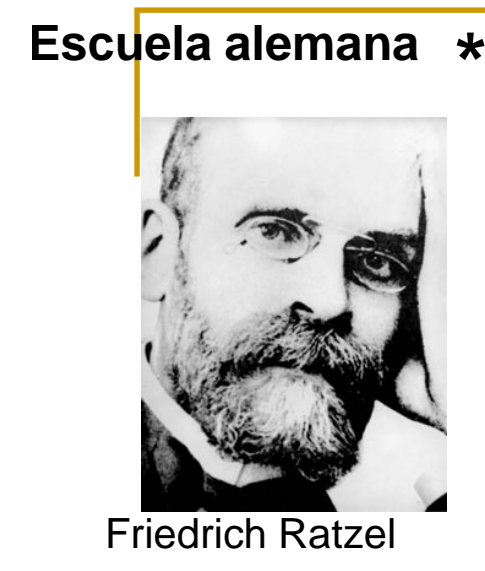

Aportes metodológicos:

Geografía ciencia empírica cuyo procedimientos de análisis son:

- observación

- descripción

- síntesis

(Dos volúmenes publicados en 1882 y 1891 y la Geografía Política (1903).

Su obra se orienta, en gran medida, al tema clásico de la diferenciación de la superficie terrestre, aunque enfocándolo específicamente en lo relativo a la diferenciación humana. El problema de la unidad de la especie humana que se manifiesta en grupos o pueblos ("razas") tan diferentes -como lo documenta la etnografía- exige una explicación que será hallada en la historia que se desarrolla sobre la Tierra, lo que da lugar a la consideración de las distintas condiciones naturales de los cuadros terrestres (Moraes, 1989).

" El estudio de la Geografía Humana consiste en intentar la comprensión de cual había sido la influencia del medio en la formación y en la ideas de la sociedad " 


\section{Otros adeptos al determinismo}

El positivismo también influyó en Francia, pudiéndose destacar la influencia de la obra Le Play (1806/82), que pone las bases para el posterior desarrollo del concepto de modo de vida. Y Reclus (1830-1905), usó método comparativo en su geografía universal.

Ellen Churchill Semple: (1863- 1932). Libros: American History and Its Geographic Conditions

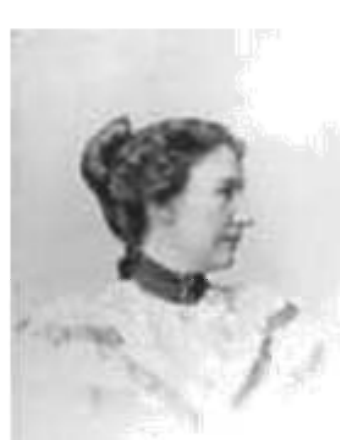

こEUU

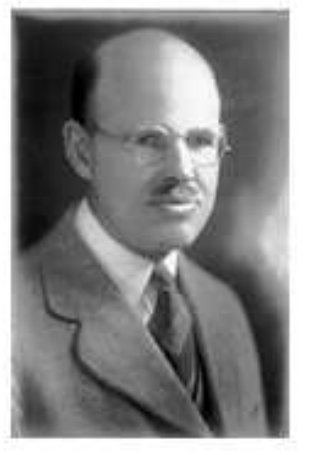

(1903) Influences of Geographic Environment (1911)

Su obra está asociada con antropogeografía y ambientalismo

El hombre es un producto de la superficie terrestre. Ello significa no sólo que el Hombre es hijo de la Tierra, polvo de su polvo, sino también que la Tierra lo protege maternalmente, alimenta, le impone tareas, dirige sus pensamientos, le enfrenta dificultades, que han fortalecido su cuerpo y agudizado su espiritu

Huntington Ellsworth (1876-1947) : Antropogeógrafo. Libro: Clima y Sociedad: define la idea de que los rigores del invierno explicarian, por las necesidades que imponen (cobijo, almacenamiento de alimentos), el gran desarrollo de la sociedad europea.

Sirve para justificar situaciones de dominación e incurre en la tendencia de naturalización de la Historia. 


\section{Escuela francesa Posibilismo geográfico}

Denominación dada por Lucien Lebvre (alumno de Vidal)

- No hay ley general

- Hay posibilidades

- Los fenómenos no se repiten

\section{una comunidad se desarrolla sobre un medio de vida}

Papel hegemónico (entre guerras 1919-1944)

* Formación Humanista

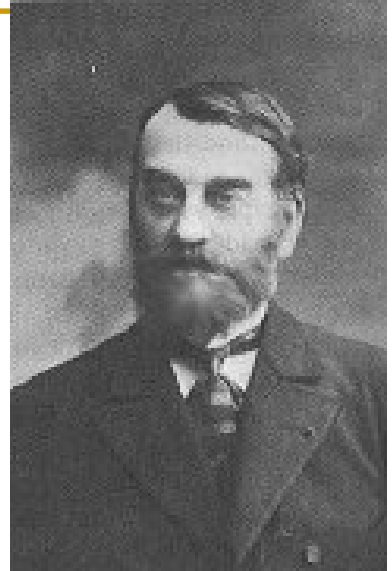

$(1845-1918)$

* Principal exponente: Paul Vidal de la Blache

En 1875 ejerce docencia en Escuela Normal Superior y entre 1899 y 1909 en la Sorbona

- Junto con Ratzel inician la concepción conceptual de lo que será la Geografía Cultural

- La teoría de Vidal de la Blache se basó en la geografía regional, cuyo objeto era la relación hombre-naturaleza, desde la perspectiva del paisaje y del estudio de la región

- Entre otros méritos cabe reconocerle el conseguir para la Geografía un status académico independiente y no como disciplina auxiliar de la historia (ESTEBANEZ, 1982)

* Fundador

-de la Revista "Annales de Géographie"

-Atlas Histoire y Geógraphie

- Cuadro de la geografía de Francia ("Tableau de la Geographie de la France", 1903), "Principios de Geografía Humana" (1922) o "Geografía Universal" (1927- 1948). 


\section{Escuela francesa:}

En los primeros escritos de Paul Vidal de la Blache se ve una decidida preocupación por establecer la cadena de causalidad que, partiendo del medio natural (de todo él o de alguna característica peculiar), llegaba hasta a explicación de las actividades humanas, o de la organización social, o aun moral, de un territorio (CAPEL, H. 1981, págs. 293-296).

Su pensamiento se funda en

-Politización del discurso: "espacio vital: pero no abandona su pensamiento progresista liberal, acorde a los intereses de la burguesía francesa expansionista de forma mas sutil: ESPECIALIZACIÓN EN GEOGRAFIA COLONIAL

- Critica carácter naturalista, pero no prescinde de esa carga:

\section{GEOGRAFÍA CIENCIA DE LOS LUGARES}

En la base de su pensamiento se refleja la influencia del filósofo espiritualista E. Boutroux (1845-1912), para el cual la característica fundamental del universo es el cambio y la evolución incesante, lo que hace que el mundo no pueda ser expresado por cualquier construcción abstracta. (URKIDI ELORRIETA, P, 1994) 


\section{Escuela francesa:}

Acentúa el componente creativo, la libertad,

contenida en la acción humana, lo que hace que la respuesta no

sea una simple imposición del medio, sino que éste ofrece abanico de posibilidades que

el Hombre elige en función de su historia.

3. Ante la postura de una acción mecanicista de la relación $\mathrm{H}-\mathrm{N}$, propone enfoque relativista:

Todo lo que atañe al Hombre esta mediatizado por la contingencia

Es la valoración que el geógrafo francés hará de la contingencia (posibilidad de que una cosa suceda o no).(URKIDI ELORRIETA, P, 1994)

* Lo que le interesa del análisis es el resultado de la

Concepto fundamental en su geografía es el de "géneros de vida" que son productos y reflexiones de una civilización y el resultado integral de unas influencias físicas, históricas y sociales que rodean la relación del hombre con el medio en un espacio concreto. Este concepto tendría tres componentes: producción material en relación a los recursos materiales, medios de nutrición, y combinación de actividades agrarias y no agrarias. (ESTEBANEZ, 1982). 


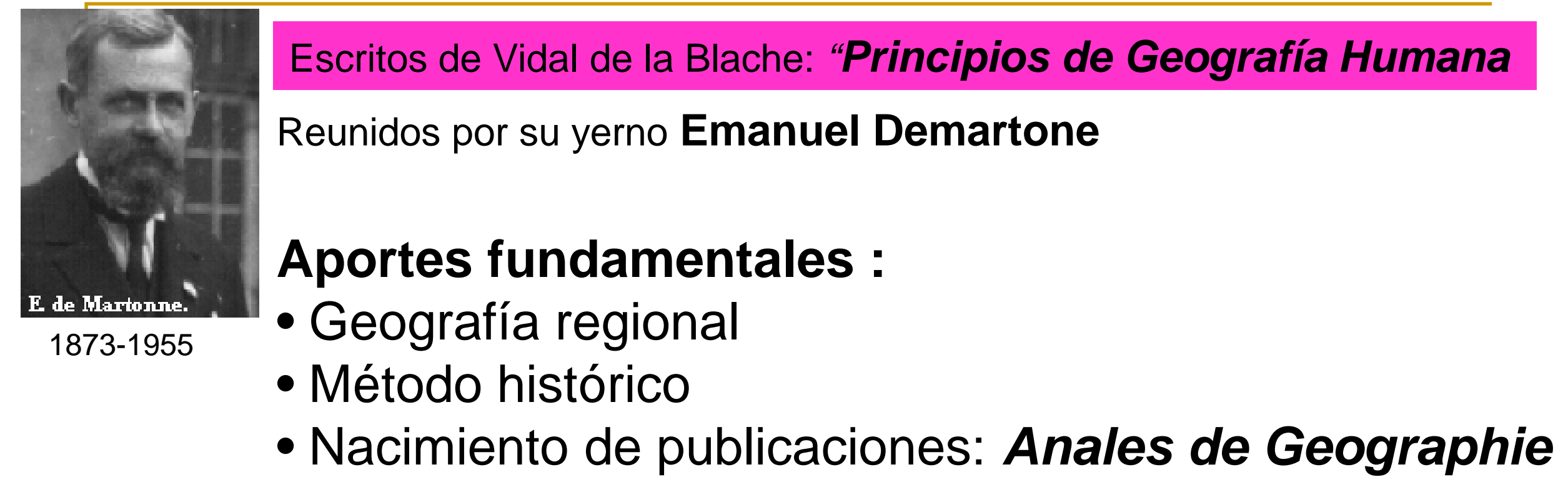

\section{* Aportes metodológicos:}

1- Partir siempre de la realidad y ajustarse a lo concreto (mapa, paisaje)

2 - Normas de trabajo: - describir - definir - explicar 


\section{Propuestas dentro de su cuerpo teórico:}

-El Hombre dispone de todo aquello que la naturaleza le permite

- Todo lo que afecta al Hombre queda sujeto a la contingencia.

•El Hombre desempeña cada vez más el papel de causa, no efecto

- Una sociedad se adapta al medio creando una relación constante y acumulativa a través de un conjunto de técnicas, hábitos, costumbres que le permite utilizar en su beneficio los recursos disponibles

Géneros de vida: concepto central en esta escuela geográfica, así como el relación entre población y recursos. Situación de equilibrio construida históricamente por las sociedades que tjenden a reproducirse de la misma forma creando normas

Desequilibrio:

movimientos migratorios o mejora de técnicas 
Hechos significativos

-Muerte de Vidal de la Blache

-2ำ Guerra Mundial

-Situación cambiante

Sintetiza cuerpo teórico, especialmente el legado ecológico vidaliano y propone nuevas vías de trabajo

Sostiene que:

1- la Geografía Humana es una meditación de la vida

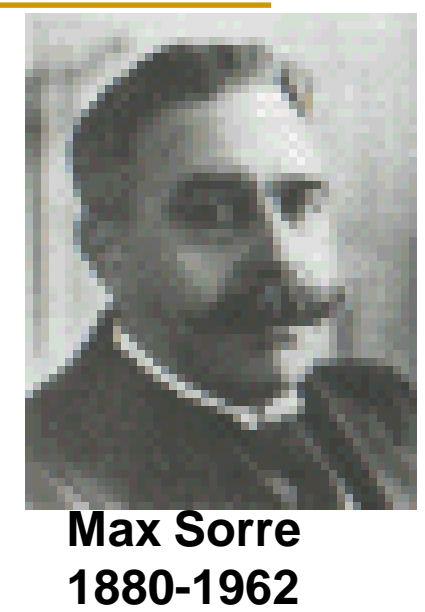

"non mortis, sed vitae meditatio est"

No muerto es vital meditar la vida

2 - La Geografía no debe abandonar el carácter holístico,

ni perder la unidad

3 - Intenta ampliar la noción: Género de vida.

"Cuando los describimos (los géneros de vida ) no debemos mutilarlos. Los elementos espirituales cuenta junto con los elementos sociales: la constitución del género de vida es inconcebible fuera de la atmósfera de una sociedad organizada". 


\section{Surge en}

\section{NEOPOSITIVISMO}

(Positivismo lógico)

- Círculo de Viena para la concepción científica del mundo. Grupo de intelectuales (1922/36) que se caracterizaban por ser:

- anti metafísica, en el análisis del lenguaje, el recurso a la lógica y su defensa de los métodos de las ciencias naturales y de las matemáticas.

- profundizaban en temas tan diversos como la Matemática, la Psicología, el análisis lógico (siguiendo la filosofía de Gottlob Frege, Ludwig Wittgenstein, Alfred North Whitehead y otros), la metodología de las ciencias empíricas (basada en Bernhard Riemann, Albert Einstein, etc.,) o la sociología positivista (con influencias que iban desde Epicuro y Jeremy Bentham, hasta John Stuart Mill y Karl Marx).

- rechazaban todo tipo de conocimiento apriorístico (anterior a la experiencia) y cualquier proposición que no pudiera ser confrontada por la experiencia. Para determinar qué enunciados podían ser aceptados como científicos propusieron el principio de demarcación o de verificabilidad

- Círculo de Berlín(1939/45) grupo de estudio organizado perteneciente a la Universidad Central de Alemania, fundado por Reichenbach .

- Tenía mucho en común con el Círculo de Viena, aunque difería en algunos temas, como la probabilidad y convencionalismos. Hacían empirismo lógico, para distinguirse del positivismo lógico del Círculo de Viena. miembros del Círculo de Berlín. Se distinguían en el análisis de las filosóficas consecuencias lógicas de los avances contemporáneos en la física y la ciencia, en particular, de la teoría de la relatividad. Negaban toda validez a la metafísica y a la filosofía tradicional 
Se origina la:

- GEOGRAFIA CUANTITATIVA O TEORICA

Se basa en principios de la lógica y de la matemática

- geOgRAFIADE LA PERCEPCION

Se basa en el comportamiento y tiene en cuenta la conducta de los seres humanos. 


\section{Paisaje: tal como se manifiesta al observador}

Sauer reactualiza en Estados Unidos la línea que, bastante tiempo antes, habían sentado otros geógrafos europeos, especialmente Hettner (con el estudio de áreas) En 1927, escribió "Los avances recientes en la geografía cultural", que considera cómo los paisajes culturales se componen de "las formas superpuestas en el paisaje físico. Instala el concepto de" morfología del paisaje" en la escuela de Berkeley (California).

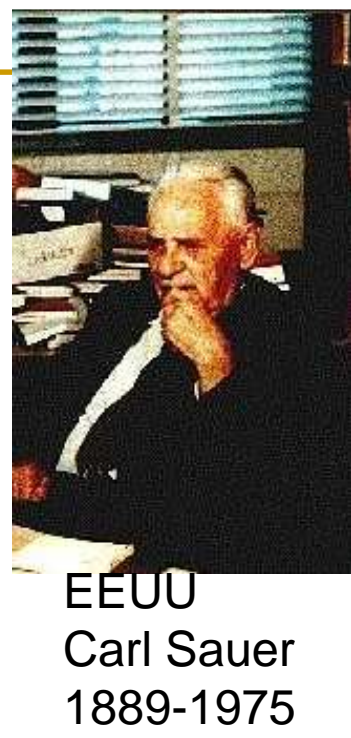

Método: inductivo.

- Analizar el cambio del paisaje natural al cultural

- Determinar diferentes fases por las que ha pasado el paisaje.

- Advertir aspectos de la ocupación humana visibles en el paisaje o en los fenómenos físicos que tienen significado en la ocupación humana

El paisaje cultural resulta del modelado del paisaje natural por un grupo humano.

La cultura es el agente, el marco natural, el medio; el paisaje cultural, el resultado

$$
\text { Geografía Histórico - Cultural }
$$

Estudio del paisaje natural significativo, a la ocupación del hombre, y a las transformaciones de este por los grupos culturales a través del tiempo 


\section{Renovación de la Geografía}

1950

Crìsis

Ruptura con enfoques desarrollados en escuelas geográficas

Nuevos caminos metodológicos

Síntesis de tendencias en la concepción de la Geografía hasta 1950

1913: Vidal de la Blache: indica que el Hombre en sí mismo no es objeto de la investigación geográfica"

1953: Trewartha: postula que la Geográfica ha de estudiar la distribución espacial y los procesos del Hombre y de sus artefactos"

1963: Ackerman: el objetivo de la geografía es "nada menos que la comprensiór de1 sistema inmenso de interacción, que comprende a toda la

humanidad y su medio ambiente natural sobre la superficie de le 


\section{Renovacịón de la Geografía}

Schaefer (EEUU): Excepcionalism in Geography", publicado en la revista Annals of the Association of American Geographers, en 1953 (publicación póstuma) de su artículo quien origina la revolución cuantitativa y teórica en Geografía.

I La Geografía es una ciencia como las demás (Y NO EXCEPCIONAL) y debe adoptar el método científico. Se debe buscar leyes que gobiernen la distribución de ciertas características sobre la superficie terrestre.

|rEl objetivo de la Geografía no está en estudiar lo que hay y por qué en ese lugar, sino las razones por las que un fenómeno aparece allí y porque no se da en otro lugar

\footnotetext{
El propósito esencial del autor es el de poner de relieve que la Geografía debe adaptar cuanto antes métodos verdaderamente científicos y originales. La expresión "excepcionalismo", que se utiliza en el título del libro, la ideó Schaefer para designar la línea de pensamiento que atribuye a la Geografía un carácter singular entre las ciencias.
} 
1950: fructífero desarrollo metodológico de las ciencias sociales

Razonamiento lógico - deductivo

Existe un orden que subyace en el caos aparente, en la organización y ocupación humana de la superficie terrestre.

Orden que puede describirse mediante la aplicación de modelos deductivos que influyen en la toma de decisiones en un contexto espacial.

Concepción del mundo OBJETIVO en el que existe un orden que aguarda ser descubierto.

Como ese orden (regularidades espaciales y co - variación de fenómenos) existe, no puede ser alterado por el observador. 


$$
\text { Razonamiento lógico - deductivo }
$$

El observador debe ser neutral y apoyarse en observaciones sobre las que han de construir una hipótesis sobre algún aspecto de la realidad, para luego comprobarla.

Leyes deben comprobarse a través de procedimientos objetivos, mediante la aplicación de matemáticas y del análisis estadístico que favorece el proceso generalizador.

Intentan producir leyes . Se "busca y se apunta a generar MODELOS", para cuya descripción y explicación colabora la Teoría de Sistemas.

FOCO Y OBJETO ESCENCIAL: ANALISIS ESPACIAL 


\section{EVOLUCIÓN DE LA GEOGRAFÍA DE LA POBLACIÓN}

NOIN - THUMERELLE

2 ETAPA: ECOLÓGICA

Hasta 1945
3 ETAPA: SISTEMATIZACIÓN 1950/70
$4^{0}$ ETAPA: CONSOLIDACIÓN

1970 hasta actualidad

PLURALIDAD

ENFOQUES

TEMAS

CONCEPTOS

MÉTODOS

Fuente: Elaboración personal, en base a García Ballesteros, A., 1994

\section{Geografía del comportamiento y de la percepción:}

-Positivistas

- Intentan modificar axiomas normativos mediante procedimientos inductivos para encontrar reglas de comportamiento para utilizarlas luego en la predicción y en explicación de formas espaciales. 


\section{Geografía del comportamiento y de la percepción}

Ante insuficiencia de modelos basados en premisas alejados de la realidad se intenta:

- descubrir qué aspecto tomaría el mundo bajo determinados supuestos de racionalidad económica en la toma de decisiones.

- comprender y descubrir excepciones y limites. Ej. Comunidades rurales

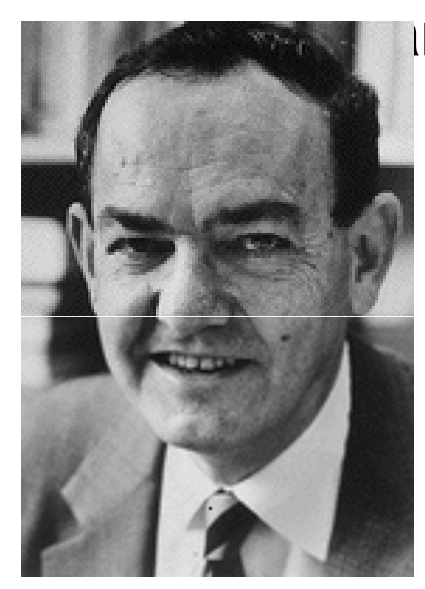

Herbert Simon nte catástrofes naturales.

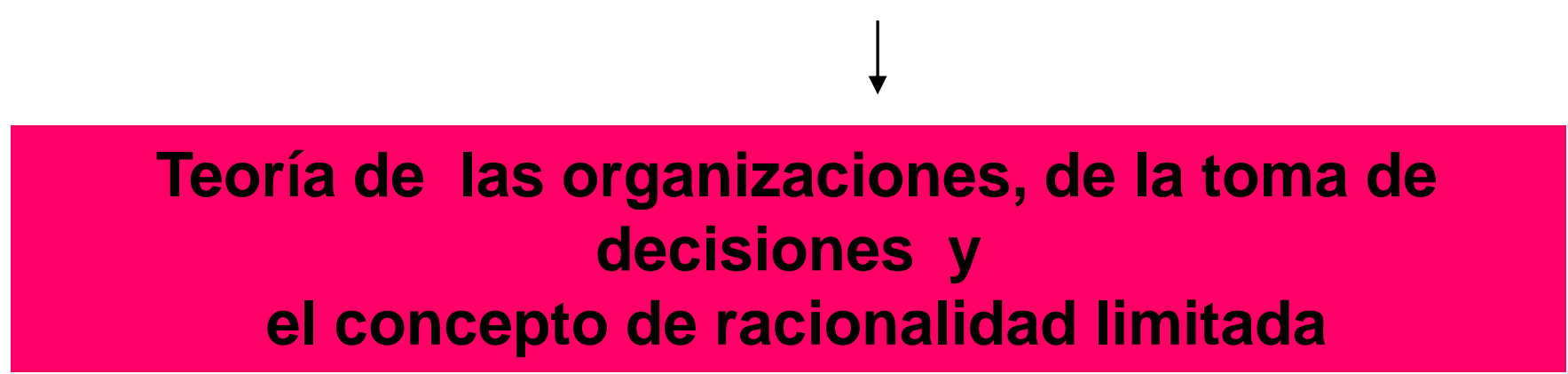

Aportó a un amplio abanico de campos, como la psicología, las matemáticas, la epistemología, la economía y la inteligencia artificia

(1916/2001)

Economista estadounidense que obtuvo el Premio Nobel de Economía en 1978 por su investigación pionera en el proceso de adopción de decisiones en las organizaciones económicas, en la que, modificando las ideas clásicas, introdujo la restricción de una información limitada, por lo que los empresarios no están capacitados para optimizar sus decisiones. 


\section{* Aportes metodológicos:}

\section{Propone esquema interpretativo}

1. Hombres son racionales cuando toman decisiones en función de:

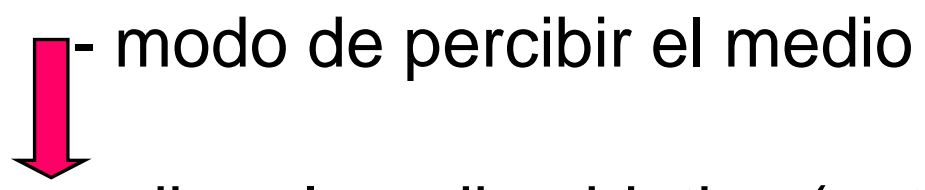

nunca percibe el medio objetivo (entre el medio real y su mente se interpone una representación, su racionalidad es limitada)

2. Hombre hace elecciones

3. Las elecciones se apoyan en el conocimiento. Pero la información es limitada (unas más informadas que otras. Depende: espacio - tiempo - edad - nivel sociocultural, etc.. 
* Aportes metodológicos: Propone esquema interpretativo

4.La información se evalúa según criterios predeterminados.

- elección habitual: criterio se apoya en la conducta anterior

- elección consciente: criterios según normativa sobre principio de máximo beneficio: cuando en la mayoría de los casos los hombres buscan lo satisfactorio y no lo óptimo

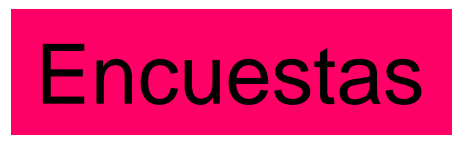

Racionalidad limitada - incertidumbre en modelos

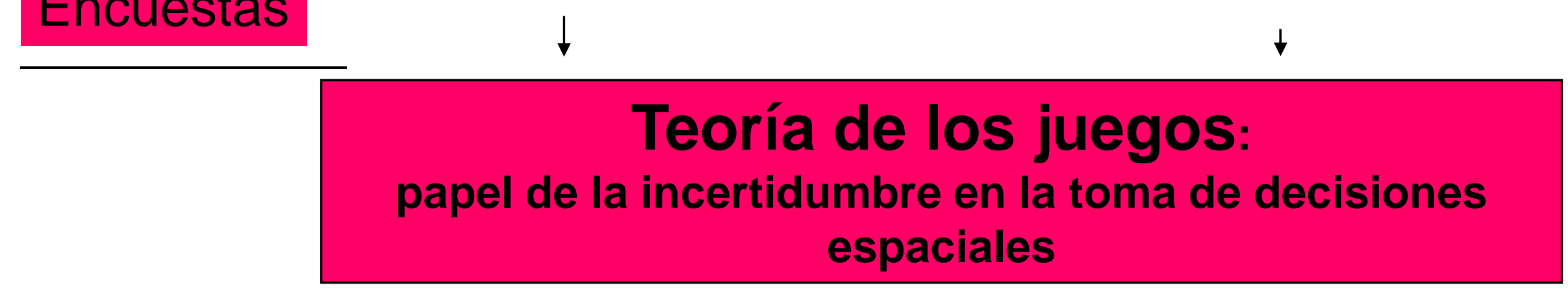

Si bien se desarrollaron técnicas de considerable valor, no se cuestionó la organización social del territorio existente 


\section{Renovación de la Geografía}

\section{En la década del '60 y '70 como consecuencia de:}

- Guerra de Corea (1950/53: Paralelo 38)

- Guerra de Vietnam (1955/75: Indochina - Camboya y Laos)

- Asesinatos de:

- Martin Luther King (Atlanta, 1929 - Memphis, 1968) defensor de los derechos civiles. Memorial discurso-I have a dream, Tengo un sueño. Nobel de la Paz 1964)

- John F. Kennedy (1917-1963), trigésimo quinto presidente de los Estados Unidos, tuvo lugar el viernes 22 de noviembre de 1963, en Dallas.

- Manifestaciones durante la Primavera de Praga y París, "Cambiar la vida (Rimbaud) transformar la sociedad (Marx)". Manifestación poder estudiantil, contra el autoritarismo, de desigualdades sociales extremas, en medio de la prosperidad económica, con las masas trabajadoras tranquilas, caracterizada por un crecimiento sostenido, de democratización, la guerra fría pasaba por una época "tibia", había más educación, y el futuro se veía promisorio. La transformación profunda de la vida cotidiana era una exigencia tanto o más importante que la igualdad social, En contra autoritarismos de sociedad tradicional y opresiva de los gobiernos, los empresarios, el clero, la familia, la escuela y los partidos

- el origen del Club de Roma: Fundado en el 1968, por 35 personalidades de 30 países, actualmente tiene su secretaría general en Hamburgo, Alemania, y cuenta con 100 miembros procedentes hoy de 38 países.

- asociación sin ánimo de lucro que reúne a científicos, economistas, hombres de negocios, grupos de influencia, actuales y anteriores Jefes de Estado de los 5 continentes. Su propósito es contribuir a mejorar nuestra sociedad, mediante la identificación y el debate activo acerca de problemas de índole global y con el convencimiento de que cada individuo puede contribuir a esta mejora. 


\section{GEOGRAFIA CRÍTICA}

Critica a la Geografía Cuantitativa. Sostiene que el geógrafo, además de estudiar la realidad, debe traducir sus conocimientos en práctica social y política activa.

Geografía Radical: cuestiona la realidad social y exige transformación

1968: revista Antipode (A radical Geography Journal) necesidad de abordar una revolución geográfica subrayando lo social

$\longrightarrow 1975$-Asociación de Geógrafos norteamericanos: vehículo de denuncias y factor de cambio social 


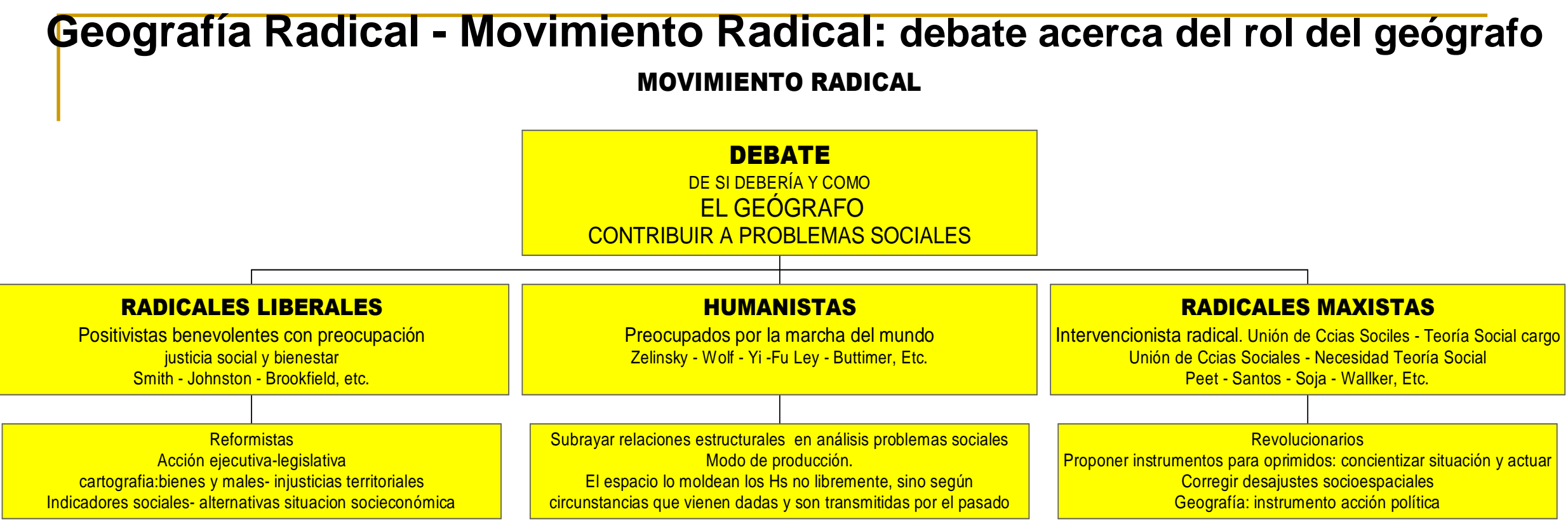

\begin{tabular}{||l||}
\hline \hline $\begin{array}{l}\text { Hurst considera que hablar del paradigma de geógrafos radicales, es una } \\
\text { denominación poco afortunada ya que incluye un abanico de personas de } \\
\text { tendencias políticas e ideológicas muy heterogéneas. }\end{array}$ \\
En 1974 realizará una crítica muy fuerte de toda la tradición cuantitativa: "es \\
relativamente fácil en Geografía de los Transportes describir en términos \\
matemáticos modelos bastante complejos sin comprender los procesos básicos \\
involucrados", como por ejemplo las relaciones entre transporte y contexto \\
económico-político. \\
Bajo esta perspectiva analiza las movilidades diferenciales en contextos \\
determinados según grupos sociales de pertenencia
\end{tabular}




\section{Geografía Crítica:}

\section{-Mas que nada una:}

- $\quad$ actitud crítica que una Geografía científica con método adecuado

- reacción contra las insuficiencias explicativas de la Geografía cuantitativa y lo que la geografía cuantitativa dejaba de lado: el comportamiento humano, las subjetividades, los sentimientos, etc.

Se han hecho retoques, unas veces dentro del sistema y otras, denuncias al positivismo, demostrando que el enfoque espacial no tiene algún valor a la hora de mejorar la calidad de vida y la condición humana.

Aunque hay que reconocer que el Positivismo bajo la forma de neopositivismo, dio organización y posicionamiento a la Geografía dentro del ámbito científico. 


\section{Estado de situación de la Geografía}

Johnston (1979). Desde 1945 aproximadamente la Geografía se encuentra en un estado de cuestionamiento del paradigma vigente, con frecuente formulaciones y críticas a las ideas dominantes, pero que no existe ningún cuerpo sólido de doctrina que sea aceptado por la mayoría de los Geógrafos

Estado de ebullición

\section{ENFOQUE ECLÉCTICO}

Geografía radical es el gran referente, en tanto la Geografía cuantitativa aporta método y técnicas de análisis, sin olvidar las propuestas humanistas en todo lo que supone una ampliación del modelo de HOMBRE Y DEL ESPACIO GEOGRÁFICO 


\section{¿Las Geografías? $\sum[1980]$}

Se comienza a hablar de «Geografías» dando lugar a los distintos posicionamientos filosóficos, epistemológicos que derivan en teorías, conceptos, metodologías y técnicas diversas, así como de compromisos socio comunitarios asumidos por el geógrafo ligados a la hora de abordar un estudio geográfico en un lugar y en tiempo determinado. En lo personal, considero pertinente hablar de la "Geografía«, como una única ciencia, con distintas perspectivas de análisis, tal como lo muestran las nuevas tendencias en los estudios de la Geografía de la Población. Rey, C. 2013.

- Busca recuperar la posición de los SERES HUMANOS como tema central de estudios, en su contexto socio histórico, económico y territorial.

- Comprensión, a través de la experiencia vivida, enfatizando en los procesos empáticos del individuo (capacidad de consustanciarse con el medio físico natural).

Estudios relacionados con Psicología y Psicología Social: se extiende a temas referidos al análisis del espacio con valoraciones y significaciones humanas que:

-permiten tomar decisiones

- dan origen ía sentimientos de pertenencia o de rechazo a un lugar

¿Cómo se manifiesta el sentido de pertenencia e identificación con el lugar?

¿De que modo se producen los movimientos casi inconscientes y cotidianos en un lugar? 


\section{Geografía Humanista:}

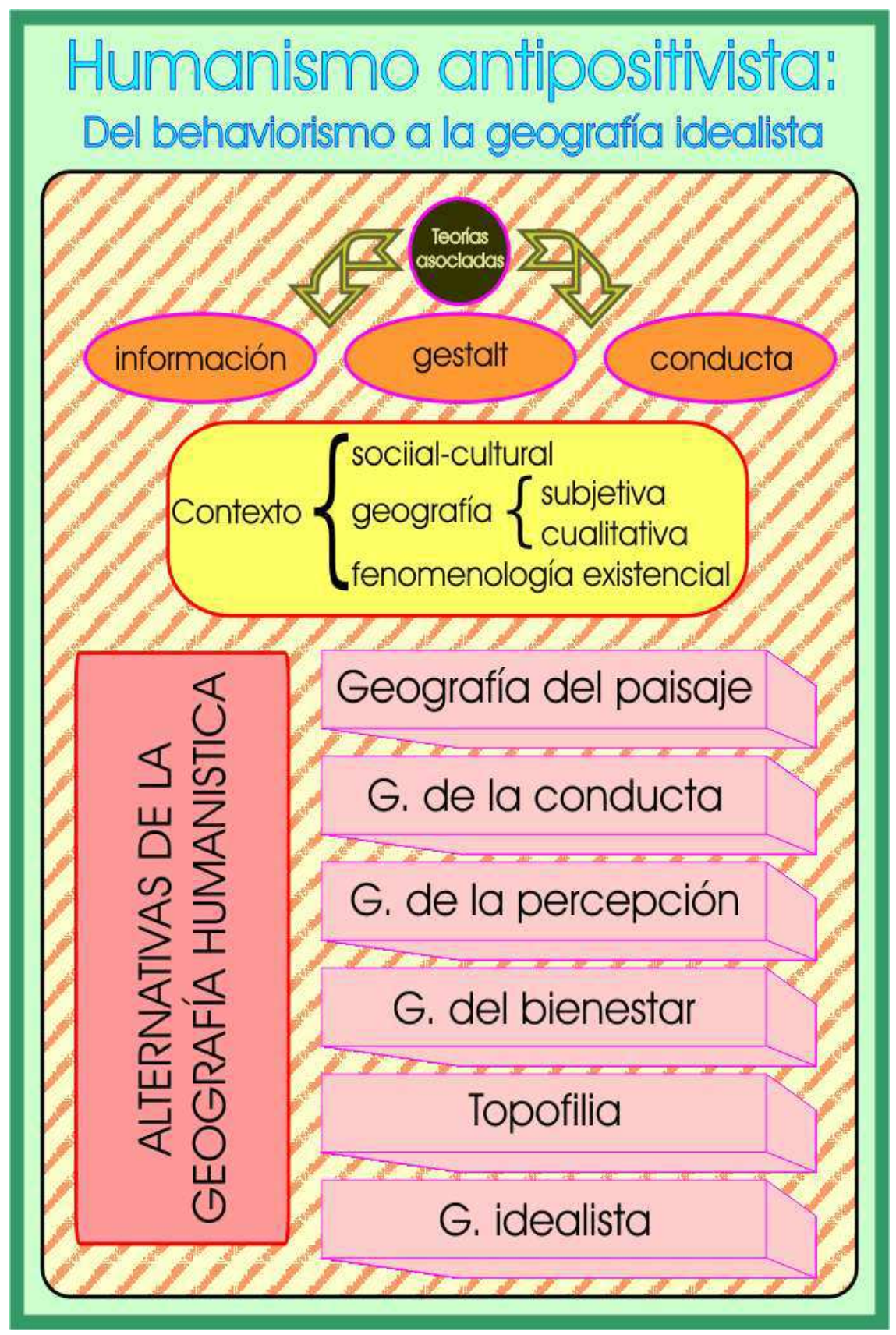

Fuente: PICKENHAYN, Jorge A. Teoría de la Geografía. Su evolución a través de la historia del pensamiento. 2005.Apuntes del Curso Postgrado. UNNE. 


\section{GEOGRAFIA HUMANISTICA}

Su principal interés está en los seres humanos sus contextos y sus implicancias. Sostiene que los geógrafos deben comprometerse con la realidad, surge junto con el Socialismo, y si bien se nutre él pero también de otros aportes que rescatan al ser humano, por ejemplo, aportes filosóficos del existencialismo (Lebus,2016).

En la actualidad, el mundo es visto y estudiado desde parcelas y la disciplina geográfica no ha sido una excepción, por ello. A manera de conclusión, se acepta que las divisiones existen, más aun cuando están instauradas. Negarlas no conduce a la solución de este conflicto creado por el mismo hombre. Se propone la integración de las geografías, en la Geografía, esto implica abandonar las posturas rígidas y sesgadas, donde los estudios de asuntos puntuales y particulares, que son necesarios, no se manejen aisladamente, porque son especificidades que responden a una totalidad, contribuyendo a su explicación. 


\section{Geografía Humanista:}

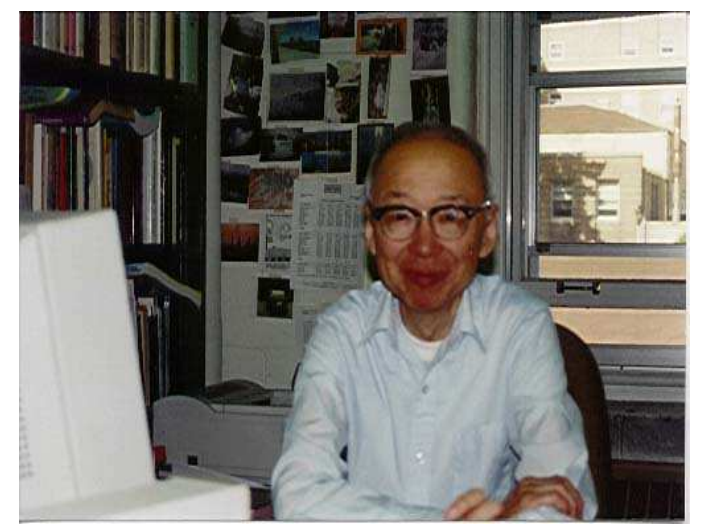

YI-FU-TUAN

Chino-estadounidense, nació en 1930 en Tianjin, China.
La visión de la Geografía humanista es holística, pero especialmente inspirada en la idea de lugar, como epicentro de una gran cantidad de señales a los que el hombre va dando significados a partir de sus propias aptitudes para decodificar los mensajes que vienen del ambiente. La experiencia valoriza al espacio en la medida que incorpora intereses, valores, pero también pensamientos y sentimientos.

En 1974 propone para su estudio los siguientes conceptos

TOPOFILIA - TOPOLATRIA -TOPOFOBIA 


\section{Geografía Humanista}

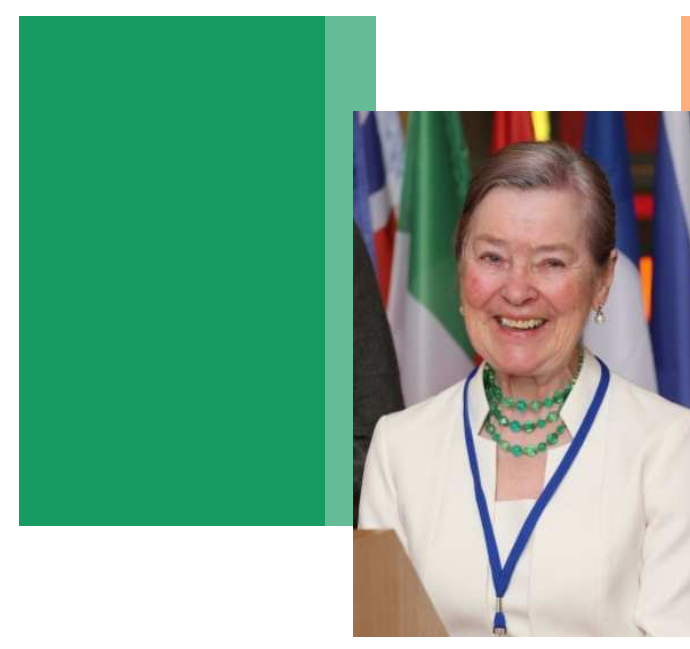

\section{Anna Buttime}

Nació en 1938,Cork, Irlanda

Está convencida que los geógrafos pueden promover un

diálogo cultural entre especialistas de las ciencias naturales y las humanidades, en temas relativos al desarrollo sustentable y el establecimiento de mejores sistemas de vida para la humanidad en nuestro planeta. 
¿ Y el papel de la Geografía de la Población dentro de las corrientes del pensamiento geográfico?

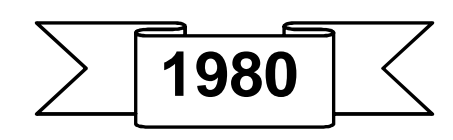

AURORA GARCIA BALLESTEROS, en 1994, DEFINE 4 ETAPAS EN LA EVOLUCIÓN DE LA GEOGRAFÍA DE LA POBLACIÓN

$>$ 1 ETAPA: ETNOLÓGICA - ANTROPOLÓGICA

$>2^{\circ}$ ETAPA: ECOLÓGICA

$>3^{\circ}$ ETAPA: SISTEMATIZACIÓN

$>4^{\circ}$ ETAPA: CONSOLIDACIÓN 


\section{¿ Y el papel de la Geografía de la Población dentro de las corrientes del pensamiento geográfico?}

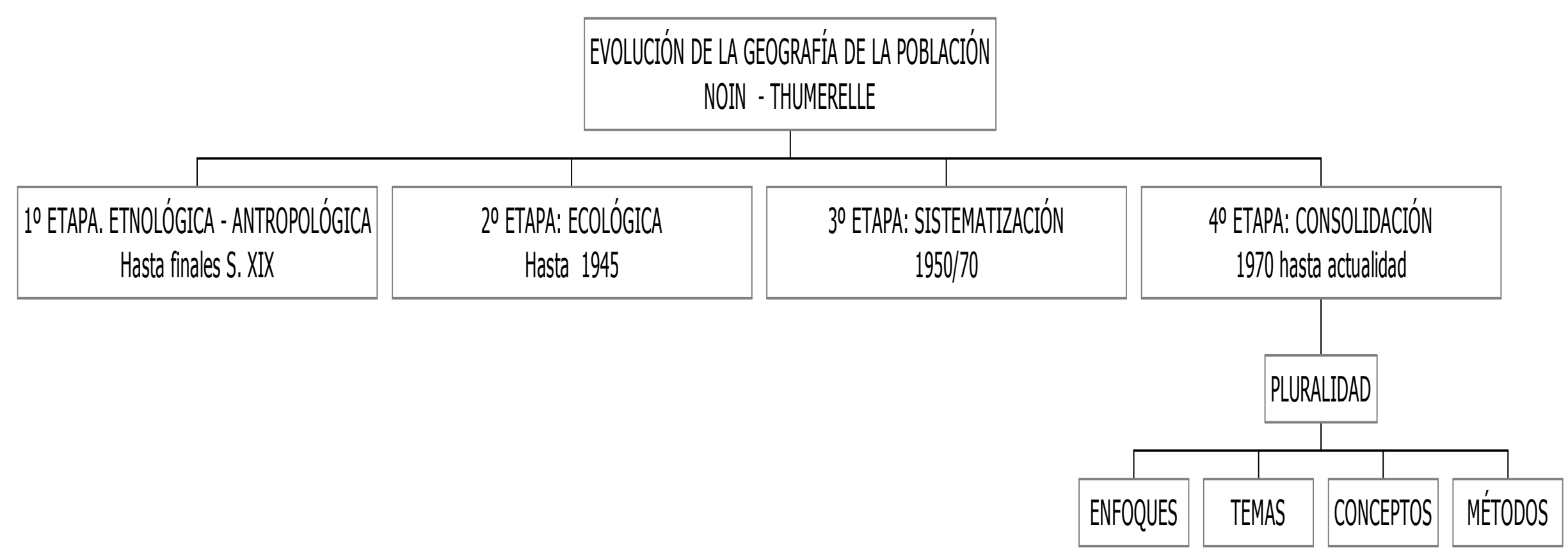


$>4^{\circ}$ ETAPA: CONSOLIDACIÓN

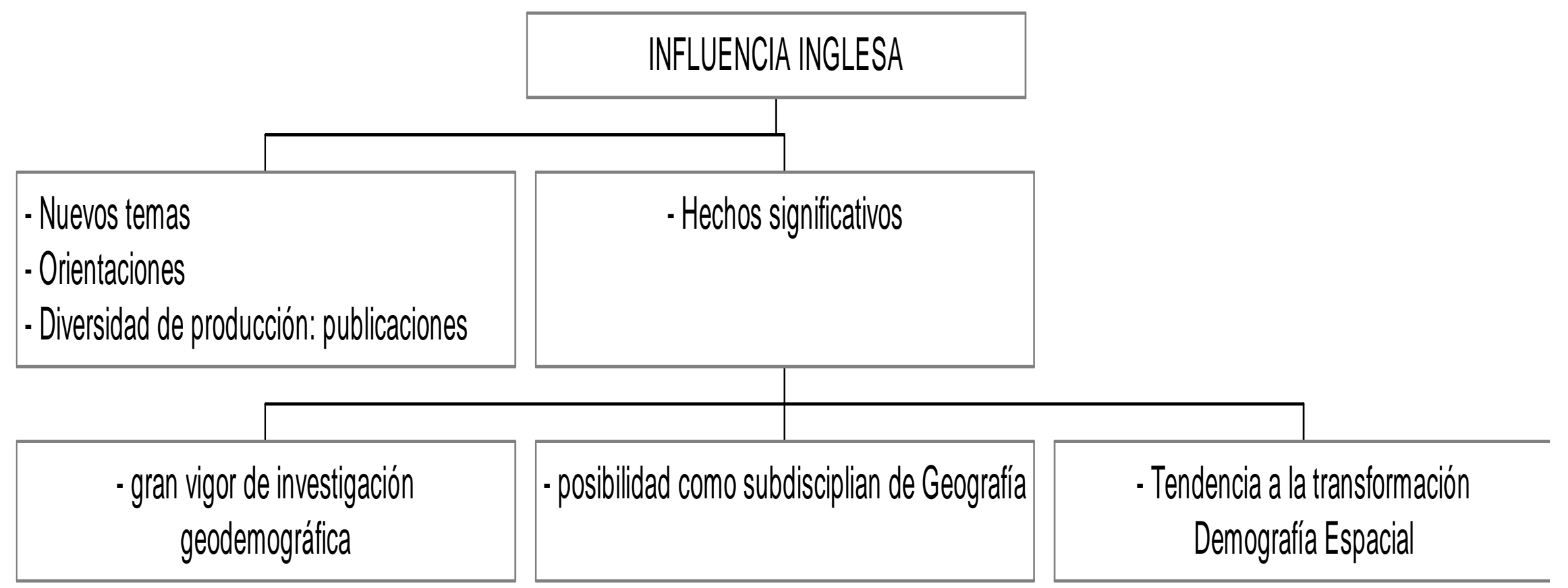

$\rightarrow$ En texto de García Ballesteros, 1994, la GEOGRAFÍA DE LA POBLACION, es mencionada como una subdisciplina científica con orientación demográfica espacial

EUFORIA POR VENTAJAS DE TÉCNICAS DEMOGRÁFICAS Y REFLEXIÓN EPISTEMOLÓFICA 
WOODS: (1984) “ El papel de los geógrafos de la población es emplear la perspectiva espacial en el análisis de las estructuras demográficas, contemplándose así mismos como demógrafos al igual que como geógrafos". 


\section{LA GEOGRAFÍA DE LA POBLACIÓN DEBE SER EL EJE VERTEBRADOR DEL CONJUNTO DE LA GEOGRAFÍA}

García Ballesteros, A. 1994 


\section{En paralelo:}

- los Geógrafos de la Población buscan su propia revolución cuantitativa en el campo de la Demografía.

- Inicio de período de desarrollo separado de la Demografía.

-Renovación de contenidos. Interés por temas: ecológicos y medioambientales, a los que se debe dar respuesta.(Haggett)

La constatación de que el medio ambiente que nos rodea carece de la domesticidad que nuestra familiaridad con él impulsa, inconscientemente, a atribuirle (Haggett, 1975) 
Grandes debates Pos- positivistas, suscitan posturas

- METODOLOGÍAS MÚLTIPLES

- alternativas humanistas

- alternativas estructuralistas

- realismos críticos

- debates sobre Geografia del Género

- TEMÁTICAS VARIADAS

- papel de la población en la crisis medio ambiental

- crisis demográfica con conceptos marxistas

Marx sostiene que no puede existir una ley demográfica universal sino que a cada forma de producción le corresponde una ley de población particular; dedicó, sin embargo, especial atención al problema bajo la forma de producción capitalista, investigando el concepto del "ejército de reserva del trabajo", "superpoblación relativa"o "población excedente relativa".

- procesos de conurbación

- migraciones: - tiempo - dirección, características de los flujos + consecuencias para el desarrollo las regiones de origen destino.

- implicancias sociales de los procesos migratorios

- relación entre población y estado: control migraciones 


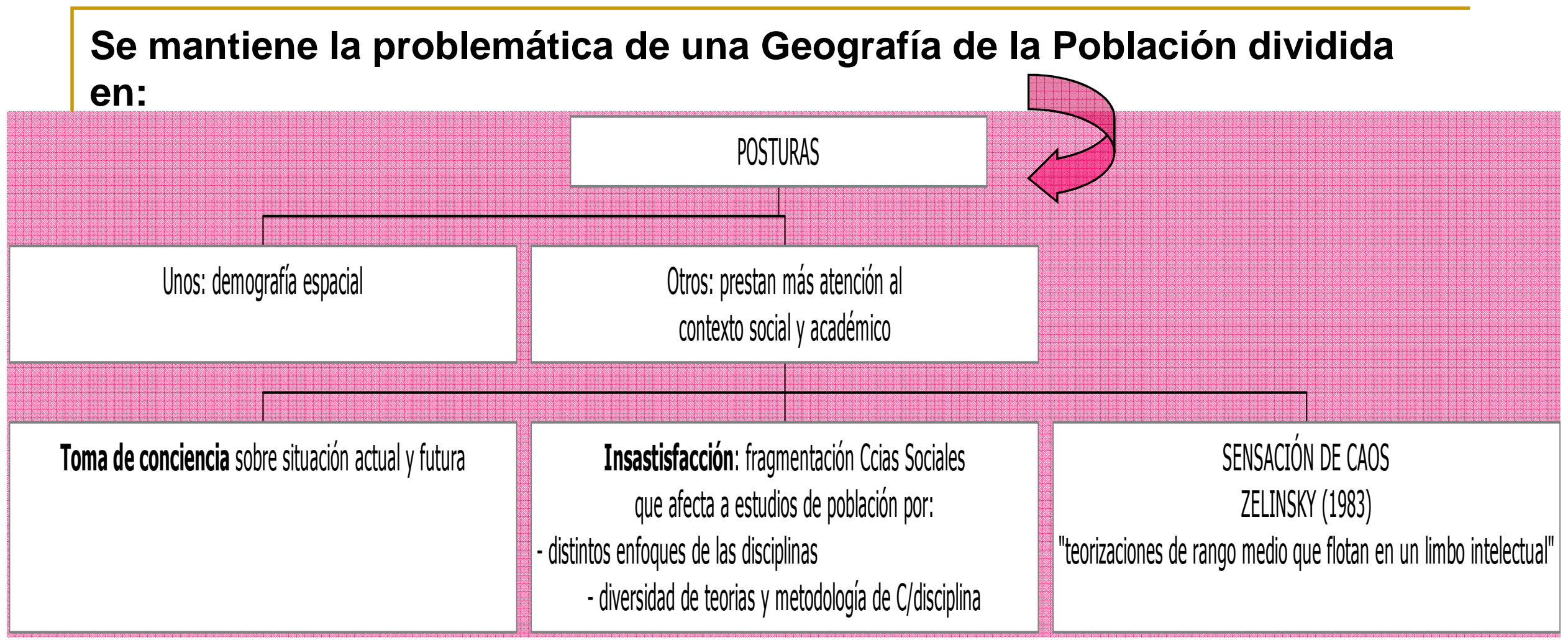

- Suceden diversos hechos que inciden en la Geografía de la Población

-Manifiesto a través de los medios de comunicación: procesos de globalización económica y política de alcance demográfico y de gran significación social: guerras, crisis ambientalesrefugiados- hambrunas

- A nivel académico una serie de hechos abren camino para la reflexión teórica y metodológica

- - se publican textos generales con difusión internacional sin coincidencia de enfoques y contenidos 


\section{Suceden diversos hechos que inciden en la Geografía de la Población}

-Manifestado a través de los medios de comunicación: procesos de globalización económica y política de alcance demográfico y de gran significación socia: guerras, crisis ambientales- refugiadoshambrunas

- A nivel académico una serie de hechos abren camino para la reflexión teórica y metodológica

- se publican textos generales con difusión internacional sin coincidencia de enfoques y contenidos

¿Éstos hechos inciden en la Geografía de la Población?. ¿Qué renuevan o qué nuevos planteos surgen? 


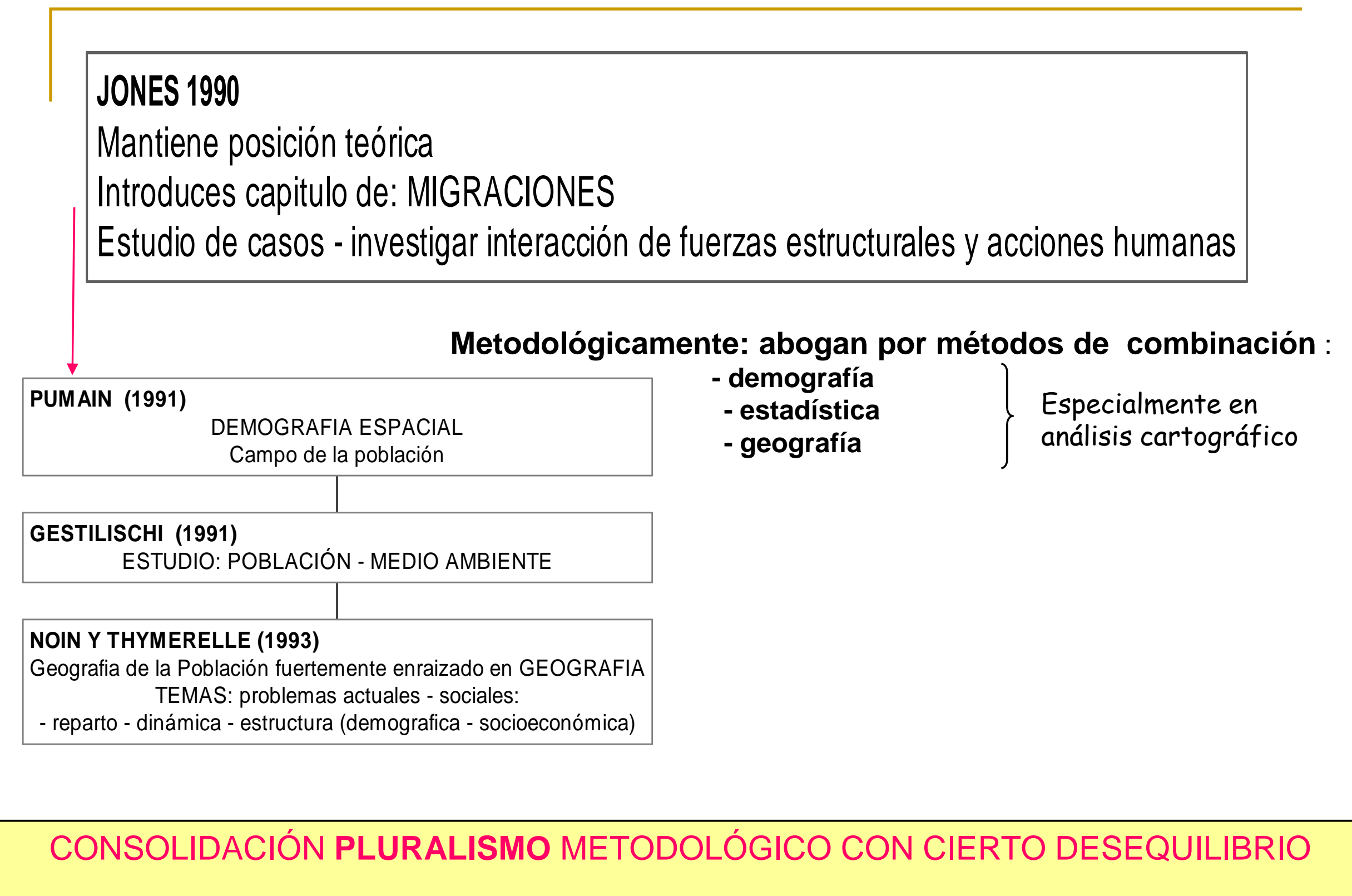




\section{PUMAIN (1991) \\ DEMOGRAFIA ESPACIAL \\ Campo de la población}

\section{GESTILISCHI (1991)}

ESTUDIO: POBLACIÓN - MEDIO AMBIENTE

\section{NOIN Y THYMERELLE (1993)}

Geografia de la Población fuertemente enraizado en GEOGRAFIA TEMAS: problemas actuales - sociales:

- reparto - dinámica - estructura (demografica - socioeconómica) 


\section{* Aportes metodológicos:}

Abogan por métodos de combinación :

- demografía

- estadística

- geografía

\section{CONSOLIDACIÓN PLURALISMO METODOLÓGICO CON CIERTO DESEQUILIBRIO}




\section{* Aportes metodológicos: \\ POSTURAS:}

$\checkmark$ rediscutir papel de teorías generales, examinando su valor como medio de ensamblar factores potencialmente interrelacionados en un sistema demográfico a la luz de teorías a nivel medio y micro relativos a lugares específicos.

$\checkmark$ enfoque: behaviosista (percepción: estudio de migraciones).

$\checkmark$ estructuralistas: conectan viejos postulados idiográficos -con aportaciones humanísticas- con la demografía: NUEVA GEOGRAFÍA REGIONAL. Propone investigar los lugares y sus experiencias de cambios y generalizaciones deben emanar del estudio de la dimensión local y de los procesos que en ellos se producen.

$\checkmark$ cualitativo: utilización de biografía.

$\checkmark$ Conexión con posturas propias del posmodernismo 


\section{GRAN VARIEDAD TEMÁTICA:}

1- TEMAS NÚCLEOS:

\section{AMigraciones}

- tener en cuenta a individuos con sus propias experiencias

- métodos cualitativos: novelas- historias de vida - relatos - cine

- estudios: - microescala

- macroescala: interpretación de corrientes migratorias en términos de

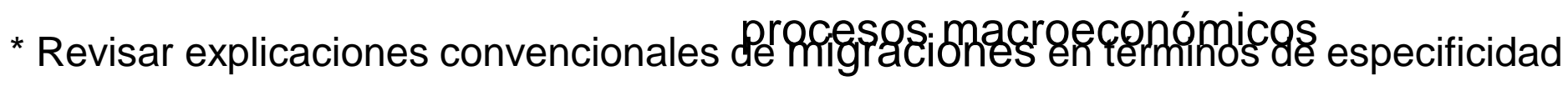

* Enfatizar la necesidad de conocimientos de los lugares

* En el contexto social - académico: impulsan estudio MIGRACIONES

* Fecundidad: continúa potente: demografía espacial:

El análisis de la fecundidad continúa muy potente, especialmente en el campo de la Demografía espacial, aunque no faltan autores como Wilson (1990), que consideran que, para la mayoría de los países desarrollados, las variaciones espaciales de la fecundidad tienen escasa importancia, por lo que se propone abandonar esta línea de investigación y reexaminar el papel de los geógrafos en este campo de estudio.

García Ballesteros , A. 2000.

Mortalidad: adquiere cierto desarrollo

- desigualdad ante la muerte

\} Indicador de procesos sociales más amplios

- patrones de distribución 


\section{2 - OTROS TEMAS:}

\section{-Subgrupos de población:}

- ancianos: conexión con gerontología social

- minorías étnicas

- género

3 - DEBATES:

눌 contexto académico: demografía espacial o mayor enraizamiento en la propia GEOGRAFÍA

Según país: DIFERENTE SITUACIÓN: - nivel de implementación

- institucionalización académica

- pluralidad.

* contexto social: restringir investigación a temas núcleos o ampliarlos, o prestar más atención a grandes problemas demográficos que acompañan a la globalización económica, política y social del mundo contemporáneo. 


\section{¿Cuál es el Futuro de GEOGRAFÍA DE LA POBLACIÓN:}

\section{¿ Debería involucrarse en estudios de problemas contemporáneos con diversas escalas de análisis espacial?}

- envejecimiento - hogares unipersonales migraciones - ancianos, etc. ...

Sólo una Geografía de la Población sensible, como señala Noin (1991), a los problemas e interrogantes del mundo actual y al papel que los hechos demográficos desempeñan en los mismos y bien insertada, por tanto, en el doble contexto social y académico, puede tener un brillante futuro. García Ballesteros, A. 2000 
B

】

B

L $\mathbb{D C A P E L}$, Horacio "Historia de la ciencia e historia de las disciplinas científicas" Universidad de

O

$\mathrm{G}$

A

$\mathrm{F}$

[DBALESTEROS, Aurora (et al.)"Teoría y práctica de la geografía”, Madrid, Alhambra, 1986.

[DOSQUE MAUREL, Joaquín y ORTEGA ALBA, Francisco "Comentario de textos geográficos. Historia y crítica del pensamiento geográfico", Barcelona, Oikos Tau, 1995.

[BREITBART, Miran (Ed.) “Anarquismo y geografía”, Barcelona, Oikos Tau, Col. Geografía 4, 1988, Barcelona, Geo-Crítica 84, pp.11 a 21, diciembre de 1989.

[DCAPEL, Horacio "Filosofía y ciencia en la geografía contem-poránea", Barcelona, Barcanova, 1981.

[DCLAVAL, Paul “Evolución de la Geografía Humana”, Barcelona, Oikos-Tau, 1981.

$\mathbb{E}$ CLAVAL, Paul “La Geografía Cultural”, Buenos Aires, Eudeba, 1999.

[DClaval, Paul. Geografía Humana y Económica contemporánea. Madrid, Akal, 1987

[DDI CIONE, Vicente (Comp.) "Geografía por venir. Cuestiones, opiniones, debates", Buenos Aires, Cooperativa Editora Universitaria. 1997.

[DESTÉBANEZ, José “Tendencias y problemática actual de la geografía”, Madrid, Cincel, 1986. 
[DGARCIA BALLESTEROS, Aurora (et al.) "Geografía y humanismo", Barcelona, Oikos Tau, Prácticas de Geografía Humana, 1992.

[DARCIA BALLESTEROS, Aurora (et al.) "Métodos y técnicas cualitativas en geografía social", Barcelona, Oikos-Tau, 1986.

I $\mathbb{L}$ GARCIA BALLESTEROS, Aurora (et al.) "Teoría y práctica de la geografía", Madrid, Alhambra, 1986.

$\mathbb{D}$ García Ballesteros, Aurora. La Geografía de la población en el último decenio del siglo XX. En: Estudios Geográficos. LV, 217. Madrid, CSIC. Centro de Investigaciones sobre economía, la sociedad y el medio (CIESM), 1994. Pp. 593-615.

$\mathbb{Q}$ García Ballesteros, Aurora. La Geografía de la población: Del enfoque regional al pluralismo epistemológico. En Teoría y Práctica de la Geografía, Madrid, Alambra Universidad, 1986. Pp.183198.

[DG GOMEZ MENDOZA (et al.) "El pensamiento geográfico", Madrid, Alianza, 1982.

$\mathbb{1}$ GOMEZ MENDOZA, Josefina "Geografías del presente y del pasado", Madrid, Alhambra, Serie Teoría y Práctica de la Geografía, 1986.

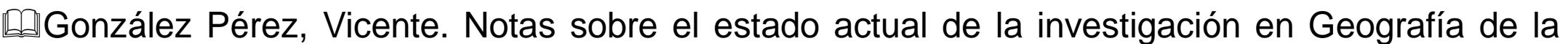
Población. En: Cuadernos de Geografía №50, Valencia, Universidad de Valencia, Facultad de Geografía e Historia, 1991.

[D] González Pérez, Vicente. Notas sobre el valor educativo de la Geografía de la Población. En: Investigaciones Geográficas №22, Madrid, Universidad de Alicante, Instituto Universitario de Geografía, 1999, pp.23-31.

[DREGORY, Derek “Ideología, ciencia y geografía humana”, Barcelona, Oikos-Tau, 1984. 


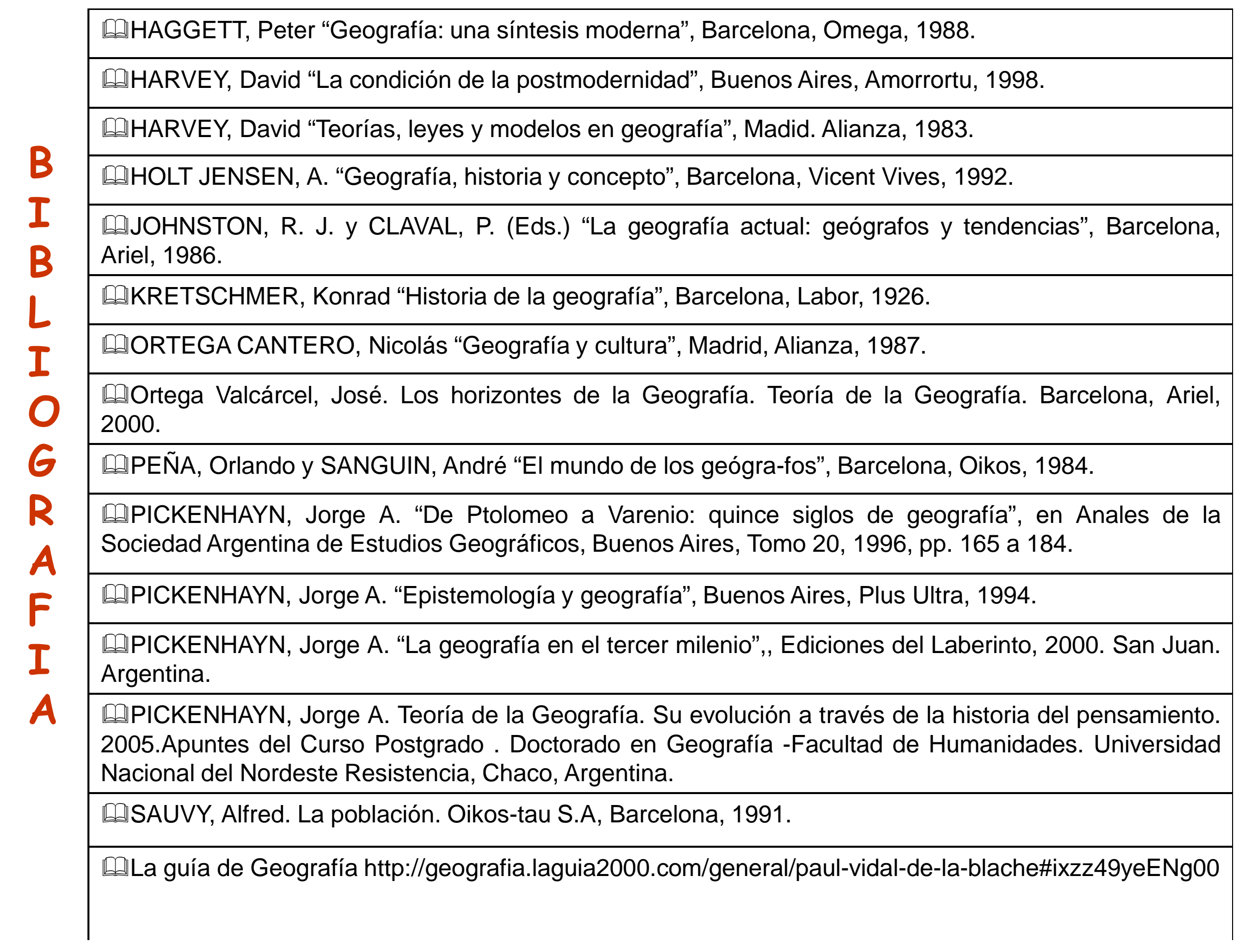

